\title{
Poder presidencial: persuasão ou ação estratégica?
}

\author{
Presidential power: persuasion or strategic action?
}

Simone Diniz ${ }^{1}$

1 Doutora em Ciência Política pela Universidade de São Paulo. Professora da Universidade Federal de São Carlos, Brasil. E-mail: dinizsimone@hotmail.com

Resenha de: EDWARDS III, George C. Predicting the presidency: the potential of persuasive leadership. Princeton: Princeton University Press, 2016. 255p.

Na década de 1960 Richard Elliot Neustadt lançou Presidential Power, uma obra que se tornou referência nos estudos sobre liderança presidencial no sistema político norte-americano. Com ele aprendemos que poderes formais atribuídos aos presidentes pelas leis ou pela Constituição não são suficientes para que chefes de governo no sistema presidencialista alcancem seus objetivos de políticas, entre outros fatores, devido a sobreposições institucionais fundadas na divisão de poderes. Em última instância, para Neustadt, o "poder presidencial" é o poder de persuadir e, o sucesso ou o fracasso presidencial é atribuído às qualidades da liderança.

Predicting the Presidency dialoga intensamente com Presidential Power, ressaltando sua influência em inúmeras análises, que enfatizam não somente que a persuasão é necessária, como também é central na obtenção de apoio do público e/ou dos membros do Congresso às iniciativas de políticas dos presidentes. No entanto, não deixa de se posicionar de forma crítica em relação a tais estudos, indicando-os como descritivos, que incentivam explicações ad hoc que desestimulam generalizações sobre o nível estratégico do poder presidencial e, des- consideram a importância do contexto no qual a presidência opera.

\section{GEORGE C. EDWARDS III \\ PREDICTING \\ THE PRESIDENCY

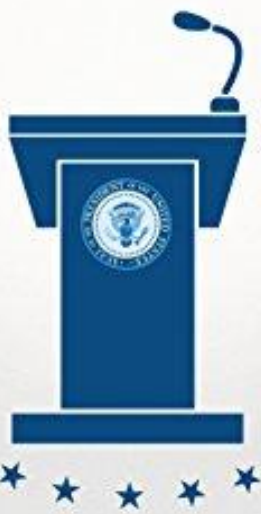

The Potential of Persuasive Leadership

O livro de Edwards III concentra-se nos dois primeiros anos do segundo mandato do Presidente Barack Obama e busca compreender os fatores que levaram o Presi- 
dente a enfrentar dificuldades na obtenção de apoio à política de saúde, de imigração, controle de armas e nas questões orçamentárias, consideradas prioritárias para o governo.

A análise está organizada em 10 capítulos. O primeiro estabelece a base conceitual para a análise do "poder presidencial" e propõe que se explore as oportunidades previamente existentes, especialmente no que diz respeito à percepção que o eleitorado e os congressistas têm sobre o presidente, à orientação geral de ambos em relação a temas específicos de políticas e, ao tamanho da base de apoio congressual do presidente.

$\mathrm{O}$ argumento central do texto é que tanto analistas quanto o próprio Presidente Obama acreditaram no "poder do púlpito presidencial". A fé na persuasão, alimentada pela habilidade retórica do Presidente, circundou boa parte da administração no decorrer do primeiro mandato e nos dois primeiros anos do segundo. Um aspecto bastante enfatizado no livro é que não se trata de falta de habilidade, determinação, ou ainda eloquência para ter sucesso. $O$ ponto importante é que o contexto no qual a presidência Obama estava inserida era tal, que havia pouca chance de sucesso no encaminhamento das iniciativas apresentadas. Dessa forma, características individuais como carisma e capacidade de estimular os legisladores, além de apelos retóricos, embora sejam fatores comumente citados como indicadores do sucesso presidencial, guardam pouca relação com a forma como a liderança é exercida. Ao pressupor que o sucesso presidencial viria das habilidades da liderança, os analistas políticos ignoraram fatos e circunstâncias que paralisaram a ação presidencial, ou seja, foram incapazes de fazer previsões acertadas sobre o desempenho do presidente.

Os capítulos 2, 3 e 4 são a demonstração empírica de tais fatos e circunstâncias. Os dois primeiros se orientam pelas seguintes questões: o presidente detinha um mandato eleitoral para suas policies? Tanto o público quanto os congressistas apoiavam as direções gerais das políticas propostas pelo presidente? Quão polarizada e quão maleável estava a opinião pública e o Congresso? O partido do presidente detinha maioria na Câmara?

Os resultados indicam um contexto político pouco favorável ao Presidente. A margem de votos recebidos no segundo mandato apresentava um pequeno acréscimo quando comparada ao primeiro; a sociedade dava sinais de polarização ideológica e apresentava resistência ao ativismo do governo. Os membros do partido republicano mantiveram maioria na Câmara dos Deputados e não compartilhavam da visão de que o Presidente teria recebido um "mandato eleitoral" para suas propostas. A polarização ideológica existente na sociedade ressoou no Congresso, minando inclusive a presença de membros moderados no interior de cada uma das bancadas partidárias.

Em resumo, a crença no "poder do púlpito" não correspondia à realidade dos fatos e a análise explicita os limites da perspectiva da persuasão para a compreensão do sucesso ou fracasso presidencial.

Os capítulos seguintes mostram certas condições que permitem aos presidentes agirem estrategicamente com vistas a obter ou consolidar apoio às suas iniciativas, por exemplo, a importância da emissão de sinais por parte da liderança, quanto a sua posição em temas específicos de políticas. Dessa sinalização não resulta o convenci- 
mento de opositores, mas ela é importante para reforçar e orientar a opinião daqueles que estão predispostos a apoiar a proposta presidencial. Consolidar o núcleo de apoiadores e/ou ativar aqueles que estão predispostos pode ser crucial para o sucesso presidencial. Nesses termos, o esforço da liderança para tranquilizar apoiadores é fundamental, fortalecendo a determinação para persistir na batalha política ou incentivar os apoiadores a serem mais ativos a favor da proposta do presidente (capítulo 5).

Outro tema abordado é o controle da agenda pública por parte do presidente. A ação estratégica consistiria em explorar as pré-disposições do público ou a sua ausência em temas específicos, de forma a evidenciar que o que é defendido pela Casa Branca é compatível com a visão do público. Os meios para se alcançar tal objetivo seriam aumentar a saliência de certas iniciativas que já são populares entre o público, que poderia resultar em maior pressão sobre os parlamentares para que estes passassem a apoia-las ou explorar a fluidez ou indiferença do público em relação a certos temas, ou ainda escolher o melhor enquadramento de forma a revelar que as escoIhas presidenciais são consistentes com os valores dos cidadãos (capítulo 6).

O capítulo 7 aborda quatro temas caros à gestão do Presidente Obama: a política antiterrorismo, que previa a prática de vigilância a e-mails e chamadas telefônicas; a ação militar na Śria; o atraso na aplicação da obrigatoriedade de que empresas com mais de 50 empregados contratassem segurosaúde para os mesmos e; a ação militar contra o estado islâmico. Os casos acima mencionados não evidenciam persuasão, mas antes, tanto partidários quanto opositores atuando em razão de sua identifica- ção ou não com o líder presidencial. Quando a política anunciada pela Casa Branca destoava da diretriz ideológica do partido do Presidente, por exemplo, no caso do atraso na implementação do seguro-saúde, Democratas apoiaram a proposta do Presidente Obama, embora contrários ao atraso e, Republicanos a princípio contrários ao seguro-saúde, ainda assim, não deram total apoio à iniciativa do Presidente, o que mostra que num contexto de alta polarização, a construção de coalizão para além do espectro partidário do presidente é pouco favorecida.

As possibilidades de interação entre a Casa Branca e o público, por meio das novas modalidades de comunicação eletrônica, são temas abordados no Capítulo 8. A principal questão que orienta o enfoque é se as novas tecnologias facilitaram o exercício da liderança presidencial, sem persuasão. 0 texto relata o esforço presidencial e de seus assessores em ampliar e potencializar o uso de redes sociais, produção de vídeos e todas as possíveis formas de interação via internet. A análise conclui que os resultados alcançados pela utilização das novas mídias são marginais, pois se por um lado, as novas modalidades de comunicação oferecem oportunidades de interação, por outro fragmentam a audiência; facilitam o contato com aqueles que já apresentavam predisposição para apoiar as iniciativas da Casa Branca, mas dificultam o contato com os não predispostos, em razão do "insulamento ideológico" típico das redes sociais.

A dependência estrutural do Presidente em relação ao seu próprio partido é enfatizada no capítulo 9. O apoio dos membros do partido da oposição é circunstancial, quando este é forçado a aderir à vontade presidencial para evitar um resultado pior 
ou em poucas ocasiões, quando pode haver concordância com as iniciativas do presidente. Dados de votação nominal em temas importantes mostram que os últimos presidentes se depararam com um cenário de declínio de apoio por parte dos membros da oposição, possivelmente em decorrência da escalada da polarização ideológica, o que acentua a dependência presidencial do apoio de seus partidários, havendo assim pouco espaço para persuasão.

No último capítulo é retomado os principais argumentos apresentados ao longo do livro, destacando a importância das avaliações estratégicas para o desempenho da liderança presidencial e a relevância do ambiente político, seja com o público e/ou com membros do Congresso para que se possa analisar a probabilidade de sucesso de uma dada gestão presidencial. Se há limites significativos para a persuasão, segue que maiores mudanças nas políticas públicas não dependem, necessariamente, da habilidade persuasiva do presidente ou de sua disposição em usá-la.

O exercício do poder presidencial é dependente das oportunidades existentes para a ação, gerando interdependência entre líderes e seguidores. Em resumo, Predicting the Presidency para além de apontar os limites analíticos quando se adota a perspectiva da persuasão, também destaca a importância de atentarmos para as ações estratégicas da liderança, para obtermos uma melhor compreensão sobre o exercício do poder presidencial.

\section{REFERÊNCIAS}

NEUSTADT, Richard. (2008), Poder Presidencial e os Presidentes Modernos: a política de liderança de Roosevelt a Reagan. Bra- sília e São Paulo: ENAP Fundação Escola Nacional de Administração Pública e Fundação Editora da UNESP.

Resenha recebida em 29 de novembro de 2017. Aprovada em 29 de novembro de 2017. 